\title{
Left ventricular aneurysm of unusual aetiology: report of two cases
}

\author{
H. HERTZEA N U, V. DEUTSCH ${ }^{1}$, J . H . Y A H I N I, \\ Y. LIEBER MA N ${ }^{2}$, a n d HENRY N. NEUFELD \\ The Heart Institute, Department of Diagnostic Radiology ${ }^{1}$, \\ and Department of Thoracic Surgery ${ }^{2}$, The Chaim Sheba Medical Center, \\ Tel-Hashomer, Tel-A viv University Medical School, Israel
}

\begin{abstract}
Hertzeanu, H., Deutsch, V., Yahini, J. H., Lieberman, Y., and Neufeld, H. N. (1976). Thorax, 31, 220-225. Left ventricular aneurysm of unusual aetiology: report of two cases Two young patients aged 14 and 25 with left ventricular aneurysms are described. In both, a clinical picture initiated by attacks of supraventricular tachycardia led to the discovery of the condition.

In the first patient the clinical picture clearly suggested a traumatic aetiology. In the second, the angiographic and histological findings strongly favoured a congenital origin. Both patients underwent successful aneurysmectomy. The literature on the incidence and aetiology of traumatic or congenital ventricular aneurysms is discussed.
\end{abstract}

Most left ventricular aneurysms (LVA) are due to coronary occlusion (Sternberg, 1914 ${ }^{1}$ ). Other aetiologies that have been described include trauma (French, 1912), rheumatic carditis (Parkinson, Bedford, and Thomson, 1938), syphilitic myocarditis (Sohval, 1935; Aronstein and Neuman, 1941), tuberculosis (Jones and Tilden, 1942 ${ }^{1}$ ), interstitial myocarditis (Beaudet and Boermans, 1947'), and mycotic infections (Eichhorn and Garvin, 1943). Burn, Hollander, and Crawford (1943), Clearkin and Bunjé (1955), Björk (1965), and Maloy et al. (1971) described congenital LVA, and Abrahams et al. (1962) reported an unusual type of annular subvalvular LVA in Nigerians which they considered to be of congenital origin. Chesler et al. (1965) described the same condition in the South African Bantu. However, whatever the aetiologies, LVA in young persons is rare. The following is a report of two additional examples of LVA in patients aged 14 and 25 , one traumatic and the other most probably of congenital origin.

\section{CASE REPORTS}

PATIENT 1 M.S., a 14-year-old boy, was born in Morocco and his family history was noncontributory. Three months before his first admission to hospital on 24 August 1963, he was hit heavily on the left chest with a ball during a ${ }^{1}$ Quoted by Clearkin and Bunje (1955) football game. He lost consciousness for $15 \stackrel{\text { ڤे }}{\frac{1}{Q}}$ minutes, recovered spontaneously, and com- $\stackrel{\varrho}{\rightleftarrows}$ plained only of weakness for the following two days. One month after this episode he became aware of retrosternal pains on effort with radiation to the left shoulder, palpitations, and shortness of breath. Palpitations recurred a number of times, and he was readmitted to hospital. The electrocardiogram (ECG) showed a supraventricular tachycardia which disappeared after treatment with digitalis. One month later he was readmitted to hospital with the same clinical picture but at this time the supraventricular 0 tachycardia responded only to intravenous procaine amide. The plain chest radiograph showed a $\frac{7}{0}$ localized bulge in the left ventricular border (Fig. 1a) which had not been seen on chest films taken $N$ before the chest injury. The patient was trans- $N$ ferred to our institute for further evaluation.

On physical examination there were no signs of heart failure; examination and palpation of the anterior chest wall were normal, and blood pressure was $120 / 80 \mathrm{mmHg}$. The heart sounds $\stackrel{\circledast}{\oplus}$ were normal and a grade I/VI systolic murmur was heard at the apex. The ECG showed signs of inferolateral myocardial infarction with persistent $\mathbb{D}$ ST elevation in leads II, III and V5 to V8. The $\frac{}{\mathbb{D}}$ serum aspartate aminotransferase (SGOT) and 2 lactic dehydrogenase (LDH) were within normal 


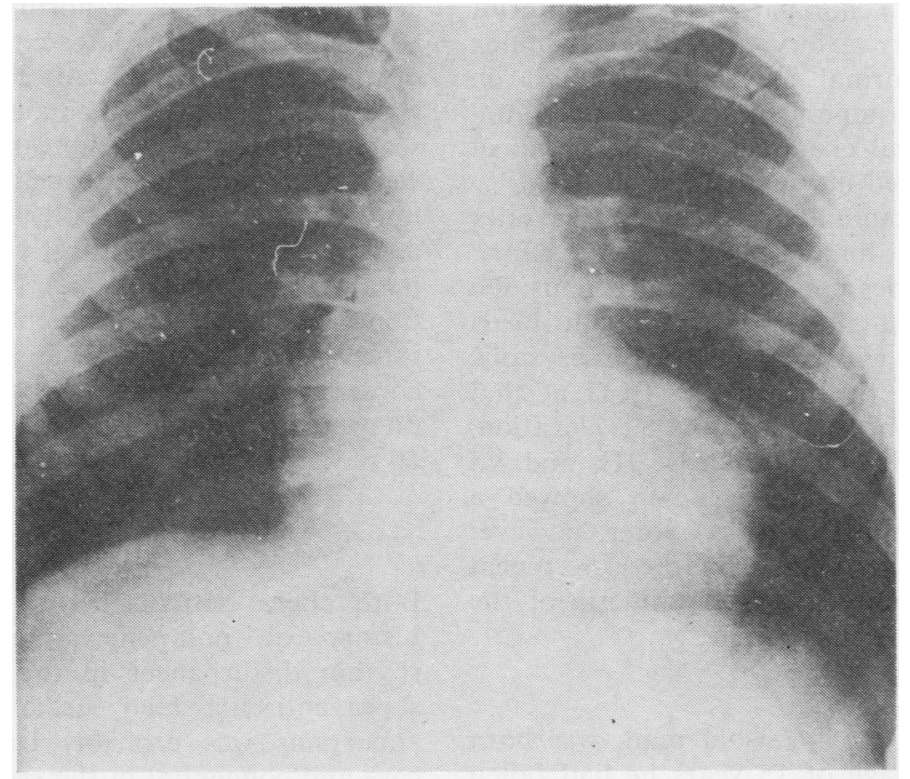

(a)

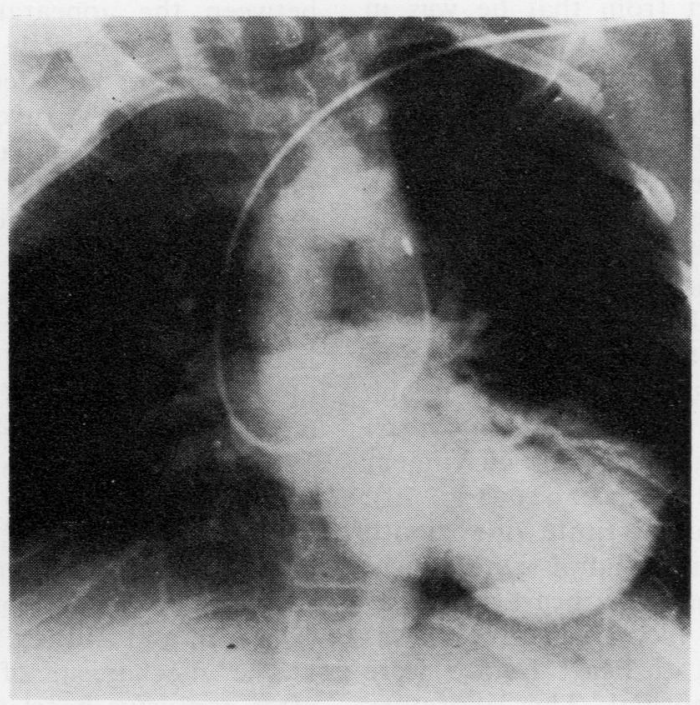

(b)

FIG. 1. (a) Plain chest radiograph shows a prominent localized bulge of the left heart border.

(b) Selective right heart angiocardiography, frontal view, demonstrates a large apical aneurysm.

limits. Right heart catheterization showed normal pressures and oxygenation. Angiocardiography revealed a large apical aneurysm of the left ventricle with paradoxical pulsations (Fig. 1b). The remainder of the ventricular wall showed good contractions. Surgical intervention was ad- vised in order to check the attacks of tachycardia and to prevent further evolution of the lesion.

At open-heart surgery an apical aneurysm, $5-6 \mathrm{~cm}$ in size, with fibrotic but very thin walls was found. The aneurysm was resected almost completely except for a small rim which was 
consolidated with a Teflon patch. The left anterior descending coronary artery and the circumflex artery appeared normal on inspection and on palpation. The postoperative course was uneventful. Histological examination of the wall of the aneurysm showed fibrous tissue only.

On follow-up examination four months later the patient's only limitation was with effort; normal daily activities presented no problems. On auscultation both a third and a fourth heart sound were audible with a grade I/VI midsystolic murmur audible at the apex. The ECG at that time revealed disappearance of the ST elevation, the $\mathrm{Q}$ waves remaining in leads II, III, and V5 to V8. The chest radiograph again showed a localized bulge of the left-heart border, however it was less prominent than before. A repeat angiocardiogram showed slight dyskinesia of the parietal wall of the left ventricle.

PATIENT 2 H.D., a 25-year-old man, was born in Tunisia. At the age of 15 years he had fallen from his bicycle and sustained a neck wound which was sutured. Apart from that he was in good health.

In November 1973 (10 years later) he was admitted to hospital because of palpitations and chest pains associated with nausea, vomiting, and shortness of breath. These symptoms had appeared suddenly while he was playing football. The blood pressure was $90 / 70 \mathrm{mmHg}$. The ECG showed supraventricular tachycardia with aberrant ventricular conduction. This reverted to sinus rhythm during an attempt to introduce an oesophageal electrode. The plain chest radiograph showed normal pulmonary markings; the heart shadow was not enlarged but a curvilinear calcification was observed at the apex (Fig. 2a). $\mathrm{He}$ was transferred to our institute one month later for further evaluation. On admission physical examination was negative. The heart rate was $78 / \mathrm{min}$ and regular; blood pressure was $120 / 70 \mathrm{mmHg}$. No signs of heart failure were present. The ECG was normal. The laboratory data, including enzymes (SGOT, creatine phosphokinase, LDH) and Casoni and Paul-Bunnel tests, were normal. Right and left heart catheterization showed normal pressures and oxygenation. Left ventriculography showed a $3 \times 3 \mathrm{~cm}$ aneurysm in the apical region, connected to the ventricle by an elongated neck (Fig. 2b). The aneurysmal sac showed diminished contraction but its neck displayed forceful and simultaneous contractions with the ventricular wall. Selective coronary arteriography showed normal coronary arteries. $\overrightarrow{\overline{\vec{D}}}$ Surgery two months later confirmed the presence of an aneurysm $(3 \times 3 \mathrm{~cm})$ connected to the apex by a muscular neck. The anterior wall of the resected aneurysm was fibrotic, and the posterior wall was calcified and very stiff with a smooth inner surface and normally shining endocardium and trabeculae. The mitral valve and the chordae tendineae appeared normal. Pathological examination of the resected specimen showed fibrous tissue intertwined with muscle fibres and normal coronary arteries. The postoperative course was uneventful and the patient was discharged after 10 days in very good condition.

\section{DISCUSSION}

Both these patients were young, with a past history of non-penetrating injury and with rhythm disturbances in the form of attacks of supraventricular tachycardia. The aetiology of the aneurysms was probably traumatic in the first case and congenital in the second.

In the first patient, the temporal relationship between the appearance of the aneurysm and the traumatic episode is convincing. The patient complained of repeated attacks of palpitation fol- $\unrhd$ lowing the injury. Investigation of these led to the $\overrightarrow{\vec{O}}$ discovery of the aneurysm. The history of this 3 patient resembles that presented by Cuendet $e t$ al. in 1966 and by Ecoiffier et al. in 1969.

In the majority of cases, cardiac damage from non-penetrating chest injury is neither recognized nor diagnosed immediately, but is recognized $\tilde{x}$ later by its complications-rhythm disturbances, tamponade, cardiac failure, or embolic phenomena (Arenberg, 1943; Liedtke and DeMuth, 1973). The frequency of arrhythmias after cardiac trauma attests to the fact that the injured heart $\frac{\text { 의 }}{5}$ is electrically unstable; ventricular fibrillation may $>$ occur at that time even though no gross or microscopic cardiac lesion can be demonstrated ô (DeMuth and Zinsser, 1965).

The mechanism of the aneurysm formation $\tilde{O}^{\circ}$

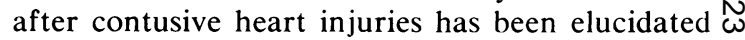
by the clinical and experimental work of Bright $\mathcal{O}$ et al. (quoted by Pupello et al., 1970). After injury 6 there is a softening and fibrotic replacement of the $\mathbb{D}$ contused myocardium. Thinning of this area may $\stackrel{\mathcal{P}}{+}$ then lead to dilatation and paradoxical systolic 꿍 pulsations of a localized area of the left ventricle; this constitutes a true aneurysm.

The coronary arteries are relatively resistant to $\stackrel{\varnothing}{\varnothing}$ injury by blunt chest trauma. Laceration of these $\overline{0}$ vessels is uncommon and thrombosis rare. Of 


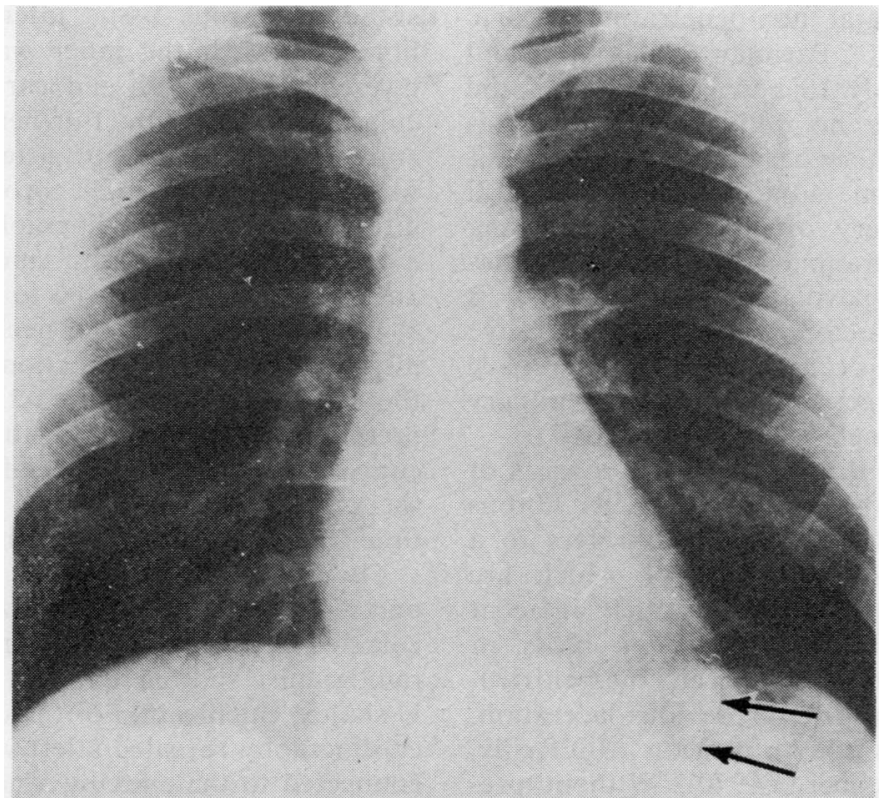

(a)

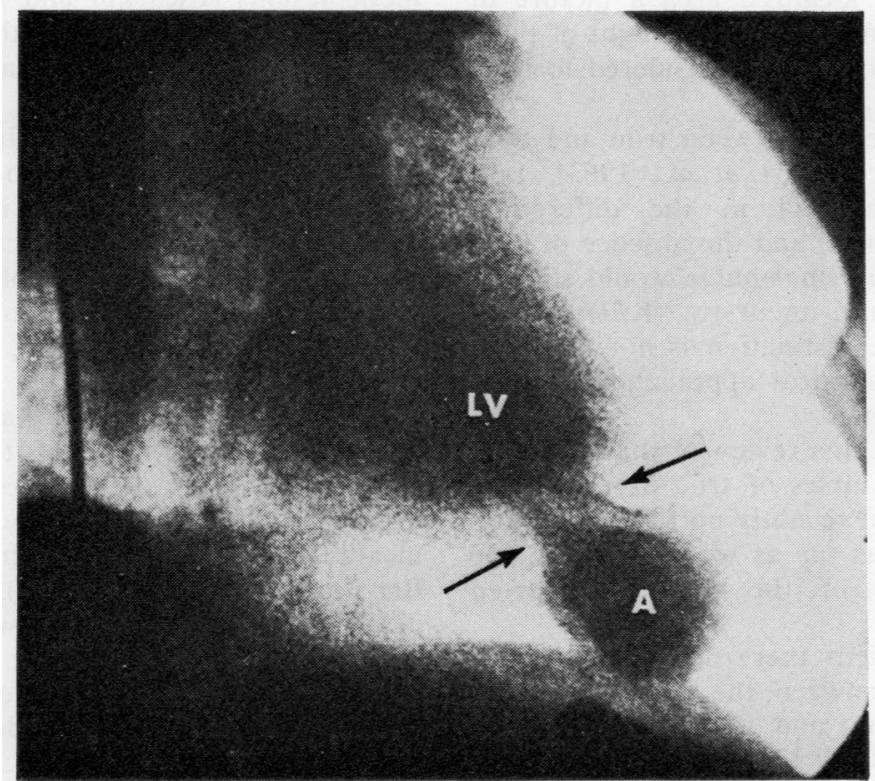

(b)

FIG. 2. (a) Plain chest radiograph. A curvilinear calcified rim is seen at the apex (arrows). (b) Selective left ventriculography, right oblique view, shows an apical aneurysm $(A)$ with a narrow neck (between arrows): $L V=$ left ventricle. 
546 patients with fatal non-penetrating cardiac injury reported by Parmley, Manion, and Mattingly (1958), only 10 had lacerations of the coronary artery with no findings of thrombosis within a coronary artery despite the frequency of myocardial contusion adjacent to extramural coronary vessels. Very often patients suffering from blunt chest trauma have other injuries which may cause hypovolaemia and shock. It is possible that these factors play a more decisive role in producing the occasionally found coronary thrombosis than direct injury to the coronary vessels (Glancy, Yarnell, and Roberts, 1967).

True aneurysm of the left ventricle consists of remnants of the myocardial wall or its fibrous tissue replacement. Pseudoaneurysm refers to a false myocardial sac, the walls of which are formed by either the pericardium, other adjacent extracardiac fibrotic tissue (Bjornsson, 1964), or both, and which communicates with the ventricular lumen through the site of previous laceration, rupture, or cardiotomy incision (O'Reilly, Kazenelson, and Spellberg, 1970). Without preexistent fibrous thickening and adhesions of the pericardium sufficient to localize and retain the escaping blood within a restricted area, cardiac tamponade and rapid death would result (Hurst, Fine, and Keyes, 1963). When the escaping blood is encapsulated in a localized area a picture of pseudoaneurysm is produced. In the light of these facts, our first patient can be considered to have had a true aneurysm.

The clinical distinction between true and false aneurysm is difficult (Hurst et al., 1963). Left ventriculography may aid in the differential diagnosis (a narrow neck and the absence of contractions of the aneurysmal bulge would support the presence of a false aneurysm (Killen et al., 1969)). However, the distinction is not of major importance for the surgical approach since it is similar in both instances.

Killen et al. (1969), in a review of the literature, reported only 19 examples of true or false posttraumatic LVA. Until recently no further reports had been published as far as we have been able to determine. Most of the patients reported underwent surgery.

In our second patient there does not seem to be any correlation between the development of symptoms and trauma, and therefore the lesion is likely to be congenital; the neck wound is probably unrelated to the cardiac findings. Furthermore, the histological and radiological findings point to a congenital aetiology; the histological findings showed that the aneurysmal wall con- sisted of fibrous tissue intertwined with muscle $\underset{\vec{\rho}}{\vec{\rho}}$ fibres but wi.h the inner wall of the aneurysm $\frac{0}{0}$ layered by a smooth endocardium; normal trabe- $\frac{0}{0}$ culae were present. Furthermore, neither vas- $\frac{\bar{\sigma}}{\bar{\omega}}$ culitis of any kind nor arteriosclerotic changes $\frac{\sigma}{\sigma}$ were seen in the small coronary vessels. In ad- $\varrho$ dition, the left ventriculography findings suggested $\%$ a congenital aneurysm, since they showed an $\overrightarrow{0}$ aneurysmal sac connected to the left ventricle by a narrow neck, both the neck and the aneurysm $\vec{\omega}$ displaying strong contractions synchronous with the left ventricular contractions. As far as the $\vec{x}$ presence of calcification in the aneurysmal wall is concerned, this is not a specific finding for any of $i$ the various aetiologies and is rather a function of $N$ time, indicating a long-standing lesion.

The patient resembles the 12-year-old boy re- 옥 ported by Shabetai and Spitz (1966) in whom a calcified left ventricular aneurysm was found. The radiographs showed cardiac enlargement and a U-shaped calcification of the cardiac apex. Angio- $\vec{\theta}$ cardiography revealed a left ventricular aneurysm connected to the apex by a narrow neck.

Only a few examples of congenital ventricular aneurysms have been described in the literature, and even in these there is some doubt as to the correct classification. For example, in some, the $\frac{\otimes}{\mathbb{Q}}$ presence of Aschoff bodies (Burn et al., 1943) or $\stackrel{2}{\Rightarrow}$ luetic lesions (Clearkin and Bunjé (1955) makes 윽 probable an aetiology other than congenital.

Vivas-Salas (1948) classified congenital aneurysms into three groups:

Group 1 includes cardiac diverticula. A cardiac diverticulum is considered to be a distinct entity and consists of an elongated muscular sac usually $\dot{\sigma}$ connected to the left ventricular apex and com- $\underline{3}$. monly associated with omphalocoele, diaphragmatic hernia, and cardiac or extracardiac malformations (Orsmond, Joffe, and Chesler, 1973; 을 Galioto et al., 1974).

In group 2 the congenital aneurysm is due to a $\frac{\overrightarrow{0}}{2}$ developmental anomaly of the muscle bundles. Burn and associates (1943) described an aneurysm or arising from the fibrous band of the mitral ring $N$ in a 13-year-old girl. Clearkin and Bunjé (1955), N Bertrand and Cooley (1955), and Björk (1965) $\sigma$ described similar patients in whom the aneurysms arose from a primary defect in the development $\stackrel{0}{\overparen{D}}$ of the muscle bundles of the left ventricle. Our $\cong$ second patient can be included in this classification.

The third group is where there is an anomalous $\underset{\mathbb{D}}{\stackrel{0}{ }}$ origin of the left coronary artery from the pul- $\frac{\mathbb{D}}{\mathbb{D}}$ monary artery. In this circumstance, inadequate oxygenation of the ventricular wall results in a 
ventricular aneurysm with or without papillary muscle dysfunction.

Complications of cardiac aneurysms include any one or more of the following: rhythm disturbances, systemic emboli, congestive heart failure, rupture or cardiac tamponade. In our patients rhythm disturbances dominated the clinical picture and constituted the main indication for surgery.

\section{REFERENCES}

Abrahams, D. G., Barton, C. J., Cockshott, W. P., Edington, G. M., and Weaver, E. J. M. (1962). Annular subvalvular left ventricular aneurysms. Quarterly Journal of Medicine, 31, 345.

Arenberg, H. (1943). Traumatic heart disease; a clinical study of 250 cases of non-penetrating chest injuries and their relation to cardiac disability. Annals of Internal Medicine, 19, 326.

Aronstein, C. G. and Neuman, L. (1941). Syphilitic aneurysm of the heart: case report with review of the literature. American Journal of Clinical Pathology, 11, 128.

Bertrand, C. A. and Cooley, R. N. (1955). Congenital aneurysm of the left ventricle: a case report. Annals of Internal Medicine, 43, 426.

Björk, V. O. (1965). Congenital left ventricular aneurysm. Thorax, 20, 190.

Bjornsson, L. (1964). Pseudoaneurysm of the left ventricle of the heart. American Journal of Clinical Pathology, 41, 302.

Burn, C. G., Hollander, A. G., and Crawford, J. H. (1943). Rare cardiac aneurysm in a child. American Heart Journal, 26, 415.

Chesler, E., Joffe, N., Schamroth, L., and Meyers, A. (1965). Annular subvalvular left ventricular aneurysms in the South African Bantu. Circulation, 32, 43.

Clearkin, K. P. and Bunjé, H. (1954). Rare cardiac aneurysm in a young adult. Thorax, 10, 42.

Cuendet, A., Mégevand, R., Moret, P., and Feuardent, R. (1966). Anévrisme traumatique du ventricule gauche opéré avec succès. Helvetica Chirurgica Acta, 33, 156.

DeMuth, W. E., Jr. and Zinsser, H. F., Jr. (1965). Myocardial contusion. Archives of Internal Medicine, 115, 434.

Ecoiffier, J., Plainfossé, M. C., Foucault, J. P., Arnaud, J., and Acar, J. (1969). Traumatisme non pénétrant du thorax chez un garçon de 17 ans: infarctus du myocarde antéro-latéral compliqué d'anévrysme parietal: étude par coronarographie. Annales de Radiologie, 12, 119.
Eichhorn, J. P. and Garvin, C. F. (1943). Myocotic aneurysm: report of a case. Annals of Internal Medicine, 19, 347.

Galioto, F. M., Jr., Reitman, M. J., Vargo, T. A., Gillette, P. C., and McNamara, D. G. (1974). Congenital diverticulum of the left ventricle. American Heart Journal, 87, 109.

Glancy, D. L., Yarnell, P., and Roberts, W. C. (1967). Traumatic left ventricular aneurysm. American Journal of Cardiology, 20, 428.

Hurst, C. O., Fine, G., and Keyes, J. W. (1963). Pseudoaneurysm of the heart: report of a case and review of literature. Circulation, 28, 427.

Killen, D. A., Gobbel, W. G., Jr., France, R., and Vix, V. A. (1969). Post-traumatic aneurysm of the left ventricle. Circulation, 39, 101.

Liedtke, A. J., and DeMuth, W. E., Jr. (1973). Nonpenetrating cardiac injuries: a collective review. American Heart Journal, 86, 687.

Maloy, W. C., Arrants, J. E., Sowell, B. F., and Hendrix, G. H. (1971). Left ventricular aneurysm of uncertain etiology with recurrent ventricular arrhythmias. New England Journal of Medicine, 285, 662 .

O'Reilly, R. J., Kazenelson, G., and Spellberg, R. D. (1970). Traumatic pseudoaneurysm of the left ventricle. American Journal of Diseases of Children, 120, 252.

Orsmond, G. S., Joffe, H. S., and Chesler, E. (1973). Congenital diverticulum of the left ventricle associated with hypoplastic right ventricle and ventricular septal defect. Circulation, 48, 1135.

Parkinson, J., Bedford, D. E., and Thomson, W. A. R. (1938). Cardiac aneurysm. Quarterly Journal of Medicine, 7, 455.

Parmley, L. F., Manion, W. C., and Mattingly, T. W. (1958). Nonpenetrating traumatic injury of the heart. Circulation, 18, 371.

Pupello, D. F., Daily, P. O., Stinson, E. B., and Shumway, N. E. (1970). Successful repair of left ventricular aneurysm due to trauma. Journal of the American Medical Association, 211, 826.

Shabetai, R. and Spitz, H. B. (1966). Calcified left ventricular aneurysm in a child. American Journal of Cardiology, 18, 781.

Sohval, A. (1935). Gumma of heart: report of two cases. Archives of Pathology, $20,429$.

Vivas-Salas, E. (1948). Cardiac aneurysm in a child seven years of age. American Journal of Diseases of Children, 75, 92.

Requests for reprints to: Dr. H. Hertzeanu, Heart Institute, The Chaim Sheba Medical Center, TelHashomer, Tel-Aviv University Medical School, Israel. 